\title{
A GREVE DE FOME E A ALIMENTAÇÃO FORÇADA: A ATUAÇÃO DO MÉDICO ANTE A AUTONOMIA DA VONTADE DO DETENTO
}

Margareth Vetis Zaganelli*

Natália Coelho Teixeira**

SUMÁRIO: Introdução. 2 O Princípio da autonomia da vontade: Breve contextualização. 3 A origem da greve de fome. 4 Legislação brasileira para a greve de fome: Dignidade bumana, autonomia da vontade e direito à vida. 5 A greve de fome na legislação estrangeira: as Declarações de Malta e de Tóquio e o Código Penal Português. 60 Conselbo Nacional de Política Criminal e Penitenciária e a greve de fome de presidiários. 7 A teoria de Robert Alexy e os direitos fundamentais. 7.1. A Teoria da Colisão entre Direitos Fundamentais. 7.2 Aplicação da teoria aos casos concretos. 8 Conclusão. Referências.

RESUMO: O artigo tem por escopo a temática da greve de fome dos presidiários, relacionando-a à autonomia da vontade e aos limites impostos a ela. Aborda-se o papel dos médicos na garantia dos direitos dos grevistas e explicita-se a legislação contemporânea sobre esse assunto. Opta-se pela apresentação de diversas visões sobre o tema, de modo a explicitar divergentes opiniões e aprofundar o entendimento do que seria dignidade humana. Fez-se uso do método descritivo, exploratório, de abordagem qualitativa, utilizando pesquisa bibliográfica, baseada em publicações científicas, reportagens e legislações nacionais e internacionais. $\mathrm{O}$ estudo adentra, ainda, a seara da autonomia da vontade, da dignidade humana e do direito à vida, ressaltando um contexto histórico que evidencia que, embora seja assunto discutido em tempo presente, encontra-se enraizado no passado e com olhar atento ao futuro.

PALAVRAS-CHAVE: Greve de fome; Presidiários; Autonomia da vontade; Dignidade humana.

\footnotetext{
"Doutora em Direito pela Universidade Federal de Minas Gerais (UFMG). Docente Titular de Direito Penal e Processual Penal e de Teoria do Direito da Universidade Federal do Espírito Santo (UFES). Docente Permanente do Programa de Pós-Graduação em Gestão Pública da Universidade Federal do Espírito Santo (UFES). Coordenadora do Grupo de Estudos e Pesquisas Direito \& Ficção. Brasil. E-mail: mvetis@terra.com.br

** Bacharelanda em Direito pela Universidade Federal do Espírito Santo (UFES), Brasil.
} 


\title{
HUNGER STRIKE AND FORCED FEEDING: THE DOCTOR'S STANCE IN THE WAKE OF THE PRISONER' S RIGHTS AND AUTONOMY
}

\begin{abstract}
Current paper deals with hunger strikes by prison inmates and their relationship with free will and the limits imposed. It also deals with the physicians role to guarantee the strikers' rights and will on the subject. There are several interpretations and different opinions on the theme, especially with regard to human dignity. Current descriptive, exploratory and qualitative paper, based on bibliographic research, analyzes scientific publications, reports, and Brazilian and international law. The study also discusses the autonomy of the will, underlining the historical context that evidences that, although currently discussed, is rooted in the past, with future perspectives.
\end{abstract}

KEY WORDS: Hunger strike; Prisoners; Free will; Human dignity.

\section{LA HUELGA DE HAMBRE Y LA ALIMENTACIÓN FORZADA: LA ACTUACIÓN DEL MÉDICO DELANTE A LA AUTONOMÍA DE LA VOLUNTAD DEL DETENTO}

RESUMEN: En el artículo se tiene por alcance la temática de la huelga de hambre de los reclusos, relacionándola a la autonomía de la voluntad y a los límites impuestos a ella. Se aborda el papel de los médicos en la garantía de los derechos de los huelguistas y se explicita la legislación contemporánea sobre ese tema. Se optó por la presentación de distintas miradas sobre el tema, de modo a explicitar divergentes opiniones y profundizar el entendimiento de lo que sería dignidad humana. Se hace uso del método descriptivo, exploratorio, de abordaje cualitativo, utilizando investigación bibliográfica, basada en publicaciones científicas, reportajes y legislaciones nacionales e internacionales. El estudio adentra, aún, a la siembra de la autonomía de la voluntad, de la dignidad humana y del derecho a la vida, resaltando un contexto histórico que evidencia que, aunque sea tema discutido en tiempo presente, se encuentra enraizado en el pasado y con mirada atenta al porvenir.

PALABRAS CLAVE: Huelga de hambre; Reclusos; Autonomía de la voluntad; Dignidad humana. 


\section{INTRODUÇÃO}

Quando se discute sobre autonomia da vontade, o pensamento comum recai sobre métodos cirúrgicos, questões de gênero ou aspectos relacionados à abreviação da vida. O princípio da autonomia da vontade, porém, abrange situações da vida muito além do que o cotidiano da maioria das pessoas retrata, como a questão da greve de fome dos presidiários.

As questões pertinentes aos presidiários nem sempre alcançam grande comoção ou mesmo discussões a respeito. Especialmente em contexto brasileiro, os presos são constantemente marginalizados e encarados por uma visão preconceituosa e que renega a dignidade inerente a sua condição de seres humanos. Entendendo essa dificuldade e a abordagem não tão ampla sobre o assunto, este artigo buscou oferecer maior atenção a essa classe e adentrar uma situação costumeira nos presídios: a greve de fome.

A greve de fome surge em contexto remoto e por diversos motivos. Caracterizou-se, principalmente, como forma de protesto contra as injustiças políticas, econômicas e sociais, bem como contra as péssimas condições de vida às quais muitos eram submetidos. Por ser assunto delicado e interferir não apenas na dinâmica social, mas em áreas relacionadas à saúde do indivíduo e ao conceito de dignidade que imperava, questionou-se até onde uma intervenção médica ou mesmo estatal na vida dos grevistas seria possível, ou seja, quais seriam os limites para a greve de fome e, consequentemente, para a autonomia da vontade da pessoa. A legislação brasileira e estrangeira incumbiu-se de responder algumas perguntas e direcionar, de certa maneira, a atuação dos presos e dos profissionais da saúde para garantir o respeito aos princípios fundamentais e orientadores da vida humana.

Este trabalho busca explicitar quais atitudes e resoluções foram adotadas pelo mundo, e especialmente no Brasil, para a questão da greve de fome. Para isso, foram utilizadas pesquisas bibliográficas, baseadas em publicações científicas, reportagens e legislações nacionais e internacionais, sem abrir mão da conjugação de aspectos sociais com a ciência do direito. Cabe ressaltar que não visa emitir sentença sobre o problema, mas mostrar e questionar diversos argumentos e entendimentos, adentrando questóes como a autonomia da vontade, a dignidade humana, o direito à vida e ressaltando um contexto histórico que prova que, embora seja assunto discutido em tempo presente, encontra-se enraizado no passado e com olhar atento ao futuro. 


\section{O PRINCÍPIO DA AUTONOMIA DA VONTADE: BREVE CONTEXTUALIZAÇÃO}

A história do mundo, seus modelos de Estado e o entendimento social dominante em cada época não podem ser visto apenas como dados curiosos ou relatos sobre o passado. Cada fase ultrapassada e cada ideologia conceituada contribui para que determinados valores sejam disseminados e positivados na sociedade. O princípio da autonomia da vontade segue esse mesmo padrão.

O mundo, em aspectos gerais, vivenciou diversos modelos de Estado. Passase pelo Estado Moderno, marcado pela concentração de poderes e desenvolvimento do comércio, e adentra-se um Estado Absolutista, com um distanciamento ainda maior entre classes detentoras de poder e a população dominada. Desde esses tempos, um caminho foi trilhado para que pudesse chegar ao Estado democrático de Direito. Ultrapassaram-se as barreiras do Estado Liberal e as mais variadas concepções do Welfare State para concretizar o entendimento de equidade e valorização do ser humano na sociedade, destacando a importância da positivação de direito fundamental, realizada pela Constituição.

Por Estado de Direito entende-se aquele que, constituído livremente com base na lei, regula por esta todas as suas decisões. Os constituintes de 1988, que deliberaram ora como iluministas, ora como iluminados, não se contentaram com a juridicidade formal, preferindo falar em Estado Democrático de Direito, que se caracteriza por levar em conta também os valores concretos da igualdade..$^{03}$

No Brasil, torna-se essencial adentrar às garantias trazidas pela Constituição de 1988, que já em seu artigo $1^{\circ}$ estabelece ser o país um Estado democrático de Direito, tendo como um de seus fundamentos a dignidade da pessoa humana.

Mas o que seria dignidade? O conceito de dignidade, extremamente subjetivo, varia de acordo com o viés histórico em que se insere. Enquanto para os cristãos a dignidade estava diretamente relacionada a um entendimento bíblico do valor atribuído ao homem por Deus, na Antiguidade ela se relacionava à posição social do indivíduo. Para o Estado democrático de Direito, cita-se o ministro Luís Roberto Barroso, que diz:

${ }^{03}$ MARTINEZ, Vinício. Estado de Direito. Revista Jus Navigandi, Teresina, ano 11, n. 918, 7 jan. 2006. Disponível em: https://jus.com.br/artigos/7786. Acesso em: 5 jul. 2017 
A dignidade humana tem seu berço secular na filosofia. Constitui, assim, em primeiro lugar, um valor, que é conceito axiológico, ligado à ideia de bom, justo, virtuoso. Nessa condição, ela se situa ao lado de outros valores centrais para o Direito, como justiça, segurança e solidariedade. É nesse plano ético que a dignidade se torna, para muitos autores, a justificação moral dos direitos humanos e dos direitos fundamentais ${ }^{04}$

Entende-se, então, que a dignidade é um princípio constitucional de extrema importância para defender os valores inerentes à pessoa humana e os direitos que nascem dessa concepção única e irrevogável. Ela orienta o ordenamento jurídico e solidifica garantias fundamentais que dela decorrem, como o princípio da autonomia da vontade. Citando novamente Barroso, "serve, assim, tanto como justificação moral quanto como fundamento normativo para os direitos fundamentais". ${ }^{05}$

Percebe-se que a autonomia da vontade provém do conceito de dignidade humana. Ela aborda a possibilidade de autodeterminação, ou seja, a capacidade da pessoa em tomar decisões próprias e possuir independência para determinar suas escolhas. Não é possível ter autonomia sem dignidade, como não é possível ser livre sem ser pessoa dotada de direitos e por isso respeitada.

Em uma concepção mais própria do direito civil, trazemos à colação Francisco Amaral ao dizer que a "autonomia da vontade é, assim, o princípio de direito privado pelo qual o agente tem a possibilidade de praticar um ato jurídico, determinandolhe o conteúdo, a forma e os efeitos" ${ }^{06}$ Semelhantemente, a Constituição reafirma esse princípio ao dizer, em inciso II do artigo $5^{\circ}$ que "ninguém será obrigado a fazer ou deixar de fazer alguma coisa senão em virtude da lei".

Nos dias atuais, diversos questionamentos e embates são travados pelas dificuldades práticas que a abordagem desse princípio traduz. Em questões médicas, por exemplo, pergunta-se qual seria o limite da atuação do médico em relação às vontades do paciente ou até que ponto a autonomia da vontade conjectura-se em liberdade ou em irresponsabilidade.

\footnotetext{
${ }^{04}$ BARROSO, Luís Roberto, A Dignidade da Pessoa Humana no Direito Constitucional Contemporâneo: Natureza Jurídica, Conteúdos Mínimos e Critérios de Aplicação. Versão provisória para debate público. Mimeografado, dezembro de 2010, p. 9 Disponível em: http://www.luisrobertobarroso.com.br/wp-content/uploads/2010/12/ Dignidade_texto-base_11dez2010.pdf. Acesso em: 13 jul. 2017

${ }^{05}$ Ibidem, p. $\overline{1} 1$

${ }^{06}$ AMARAL, Francisco. Direito Civil: introdução. 7. ed. Rio de Janeiro: Renovar, 2008, p. 383
} 
Neste trabalho, faz-se um corte metodológico e focaliza-se a visão à situação de pessoas, em especial os presos, que realizam a greve de fome. Quais são os limites de suas atitudes? A autonomia da vontade permite que suas ações sejam respeitadas independentemente das consequências que gerariam para si? É possível ao médico ou ao sistema prisional interferir nas escolhas próprias do preso?

Esses e demais questionamentos comprovam a importância da autonomia da vontade nos mais variados âmbitos da vida contemporânea, destacando a legislação e as discussões que sobre ela já incidem.

\section{A ORIGEM DA GREVE DE FOME}

A greve de fome foi consolidada como uma forma pacífica de protesto, em que o indivíduo permanece sem alimentar-se por determinado período de tempo. Nela, é comum evitar-se apenas alimentos sólidos, permanecendo a ingerir líquidos, de forma a não causar maiores complicações ao organismo.

Suas origens não são recentes, remetendo ao século VIII, quando, na Irlanda, era comum a cobrança de dívidas e reparações por meio de jejuns realizados frente ao ofensor. A prática foi adotada séculos depois pelo Exército Republicano Irlandês, que lutava contra o governo britânico pela separação da Irlanda do Norte do Reino Unido.

$\mathrm{Na}$ Índia, a greve de fome adquire maior proporção com a luta pacífica de Mahatma Gandhi contra a colonização britânica. O líder entendia que a greve era lutar abdicando da violência e suas atitudes foram temidas pelo grande impacto que uma possível morte sua provocaria no mundo. Vale ressaltar que Gandhi não prolongava seu jejum além de 21 dias, deixando claro o caráter de protesto de suas ações.

No contexto brasileiro, o período da ditadura foi propício para que diversos presos praticassem a greve de fome. Uma delas caracterizou, em 1979, a forma em que os presos posicionaram-se politicamente, pedindo a anistia; durou 32 dias e culminou na aprovação da Lei de Anistia, no mesmo ano.

Outro importante registro da história, relacionando-se diretamente ao assunto deste artigo, foi a manifestação praticada pelas sufragistas norte-americanas, que lutavam pelos direitos das mulheres, principalmente pelo direito ao voto. Uma de suas estratégias foi usar a greve de fome como forma de contornar as dificuldades impostas à luta pelos constantes aprisonamentos das denominadas "suffragettes". 
Em 1912, a famosa suffragette Emmeline foi presa e negou-se a alimentar-se, perpetuando o caráter de protesto da greve de fome. Coube à polícia alimentar as detentas de forma impositiva. Elas eram postas em liberdade quando sua saúde mostrava-se em estado extremamente crítico e presas novamente se recuperassem o bom estado e retomassem os posicionamentos políticos. Muitas mulheres morreram ao serem alimentadas compulsoriamente nas cadeias.

Embora não se negue que a greve de fome possa ser realizada como prática do suicídio, a história mostra que seu caráter é primordialmente o de protesto. Nas cadeias, muitos presos realizam a greve de forma a reivindicar melhores condições de vida, tratamentos mais adequados e o respeito à dignidade humana. Muitos são submetidos a maus-tratos e convivem diariamente com os conflitos internos dos presídios, que, na teoria, não deveriam existir. Caso que comprova esse caráter foi a greve de fome realizada pelos presos em Guantánamo, uma prisão militar dos Estados Unidos da América, em Cuba.

O exemplo mais claro é o dos presos enclausurados indefinidamente em Guantánamo. A prisão, dividida em três campos e construída em um arrendamento perpétuo de área anteriormente pertencente a Cuba, é mundialmente conhecida pelas ilegalidades e afrontas aos direitos humanos. Além da questão política, traduzida na construção de um inimigo por parte dos Estados Unidos utilizando-se exaustivamente a ideia de terrorismo, os encarcerados em greve de fome lutavam pela efetivação de direitos humanos consagrados inclusive em acordos e tratados internacionais dos quais o Estado americano é signatário. Al-Kandari, um dos grevistas, assim como outros 85 detentos, já havia sido liberado para soltura, porém continuava detido sem qualquer acusação até 2013. Muitos, presos sem julgamento há mais de uma década, alguns liberados, mas não libertados, ao iniciarem a greve de fome, chamaram a atenção do mundo não só para o fato da ideologia política que envolve as detenções, mas também para a omissão em relação à dignidade humana mínima. ${ }^{07}$

O grande problema desse tipo de manifestação são os limites que o corpo humano impõe. Uma pessoa comum pode ficar em jejum por até 60 dias, embora esse

\footnotetext{
${ }^{07}$ LIEBL, Caroline. Greve de Fome: o Mito do Meio Não Violento de Resolução de Conflitos. Rev. Fac. Dir. Sul de Minas, Pouso Alegre, v. 31, n. 2, p. 77-104, p. 88 e 89, jul./dez. 2015. Disponível em: http://www.fdsm.edu. br/adm/artigos/418ff255817260b3c6d54b712ae68441.pdf. Acesso em: 13 jul. 2017.
} 
prazo varie de acordo com as individualidades. Com o passar do tempo, o organismo passa a consumir gordura corporal para a produção de energia, ocasionando redução do peso progressivamente e, caso a greve continue, o consumo de músculos e órgãos. Além disso, os efeitos podem variar, atingindo não somente o físico, mas também o psicológico. O grevista pode sofrer de apatia, perda de concentração, dificuldade de locomoção, irritabilidade, insônia, entre muitos outros efeitos.

Se realizada por muito tempo, a greve de fome pode levar à morte e é principalmente sobre essa preocupação que incide os questionamentos a respeito da dignidade humana, da autonomia da vontade e da atuação do sistema sobre o indivíduo. Questiona-se o dever do médico, profissional comprometido com a preservação da integridade física e mental do indivíduo, ao permitir a greve de fome, ainda que esta assuma caráter de manifestação, sabendo das possíveis complicações que podem dela decorrer.

Além disso, o médico responsável pelo cuidado para com os grevistas responde não somente ao paciente, mas à administração que o contrata. Quando se vê em situação de responsabilidade pela vida de um grevista em estágio avançado, o médico precisa decidir entre o respeito à vontade do paciente e o interesse de seu empregador na manutenção da vida e da ordem. Como bem ressaltado em artigo publicado pelo periódico espanhol El País, não se trata apenas da discussão sobre a moralidade da alimentação forçada, mas dos limites impostos aos médicos que cuidam de pacientes que, embora tenham perdido a liberdade, ainda possuem outros direitos ${ }^{08}$.

Daí a importância de uma legislação definida e do intenso debate a respeito do tema, buscando orientar a atuação do médico e evitar o seu confronto moral sobre o que seria primordial para a manutenção da dignidade humana tão defendida.

Tendo tudo já exposto, volta-se à questão principal e passa-se à análise do problema na legislação nacional e no entendimento global, nos quais se coloca a autonomia da vontade, proveniente da dignidade humana, em conflito com a mesma e gera-se um embate entre garantias fundamentais: a greve de fome, assegurada pela autonomia da vontade, fere ou reafirma a dignidade humana?

\footnotetext{
${ }^{08}$ Cf. SANCHEZ, Vicente Martín; GUERRERO, Julio García. El dilema del médico ante la huelga de hambre. El País, 2006. Disponível em: https://elpais.com/diario/2006/12/19/salud/1166482804_850215.html. Acesso em: 10 mar. 2018.
} 


\section{LEGISLAÇÃO BRASILEIRA PARA A GREVE DE FOME: DIGNIDADE HUMANA, AUTONOMIA DA VONTADE E DIREITO À VIDA}

A dignidade humana é um valor coletivo. Essa assertiva foi confirmada pela Comissão das Nações Unidas para os Direitos Humanos, em 2002, no julgamento do famoso caso do arremesso de anões. Cabe explicitar um pouco a história.

$\mathrm{O}$ arremesso de anões era uma prática comum em bares, onde anões, devidamente trajados, eram arremessados em colchões por outras pessoas, em uma espécie de disputa para decidir quem alcançaria maior distância com seu lançamento. Embora os anões alegassem que a atividade era realizada com seu consentimento e que proibi-la seria impedir a forma com a qual ganhavam seu sustento, a cidade francesa Morsang-sur-Orge, em 1992, baniu a atividade. Diversos questionamentos foram levantados, como a relevância do arremesso de anões como questão de ordem pública ou conflitante do princípio da dignidade humana. Em setembro de 2002, a Comissão das Nações Unidas para os Direitos Humanos decidiu pelo banimento do arremesso de anões, ressaltando os valores supracitados e prezando pelo bem comum.

Faz-se uma analogia à greve de fome realizada pelos presidiários. Se por um lado defende-se a autonomia da vontade e o direito de autodeterminação ao seu corpo e sua vida, por outro questiona-se se é possível ser conivente com atos que atacam o conceito de vida digna estabelecido socialmente. Da mesma forma que o arremesso de anóes era um ato conscientemente tomado e relevante à vida daquele que o praticava, a greve de fome se individualiza na figura do praticante. Apesar disso, por inserir-se em um contexto social, as ações a serem analisadas pelo Estado não podem ser vistas como meros atos individuais. Desse entendimento parte a decisão que se baseia na dignidade humana como um princípio que deve ser defendido, propagado e normalizado além de vontades particulares. As vontades particulares primeiramente devem decorrer da dignidade.

Esse embate leva muitos a entenderem ser aceitável a interferência de médicos ou mesmo a alimentação forçada daqueles que a praticam, ainda que isso contradiga a autonomia da vontade. Alega-se, nesse caso, que não se saberia se a vontade da pessoa estaria viciada pelos problemas que enfrenta ou pelos próprios distúrbios que a greve geraria com o tempo, como já mencionado, além de considerar-se inaceitável tais condições de saúde em casos em que a greve de fome encontra-se em estágio avançado. 
Apesar disso, cabe argumentar que ocorre uma diferenciação entre o caso do arremesso de anões e a greve de fome, que se dá em limites ínfimos e imperceptíveis sob olhar descuidado. O limite se dá entre a interferência ou não da autonomia da vontade no princípio da dignidade humana. Interferiria a autonomia da vontade, consagrada na realização da greve, tanto na dignidade humana, valor coletivo, como foi entendido que o arremesso de anões assim o faria? Cabe analisar até que ponto a greve propaga a desordem social, como a cultura de discriminação que o arremesso poderia estabilizar, ou qual seria a magnitude de seu caráter nocivo.

Ainda relacionando dignidade humana e autonomia da vontade, questionase também o direito à vida defendido socialmente. A Constituição brasileira, em seu artigo $5^{\circ}$, diz serem todos iguais perante a lei, sendo invioláveis o direito à vida, à liberdade e à segurança.

Os contrários à prática da greve de fome podem alegar ser inadmissível a aceitação de uma prática que viole o direito à vida, direito fundamental e constitucionalmente propagado. Não se considera, porém, nesse viés, até que ponto a vida seria um direito ou um dever. Se opta pela consideração, torna-se cabível entendimento de que a dignidade humana concretiza-se em um poder de autodeterminação e que proteger a vida significa proteger também a autonomia em decidir como ela será vivida. Ressalta-se que tudo isso se solidifica desde que não fira a noção coletiva e acarrete danos à ordem social e à própria propagação da dignidade em gerações futuras, como foi acatado no caso relativo aos anões.

Nesse sentido, Pablo Simón Lorda é claro ao defender sua opinião em favor do direito dos presos à greve de fome, desde que não comprometa a saúde pública.

Pero "protección" de los derechos no implica "intromisión" en la manera de ejercerlos. El deber de velar por la integridad de los reclusos es, fundamentalmente, un deber negativo. Eso quiere decir obligación de poner a su disposición todos los medios posibles para que estén adecuada y sanamente alimentados, para evitar que se contagien de enfermedades como el sida o la tuberculosis, para protegerlos de la violencia física o sexual, etcétera. Pero no puede implicar que la Administración penitenciaria "obligue positivamente", salvo excepciones como la de la salud pública, a los reclusos a emplear esos medios. Ello supondría una clara intromisión en su libertad personal, con ribetes totalitarios. Y eso un Estado 
Democrático de Derecho no puede permitírselo. ${ }^{09}$

Por esses e outros motivos, visando esclarecer as dúvidas levantadas e permitir atitudes conforme os valores constitucionais defendidos, a legislação incumbiu-se de determinar códigos de conduta a serem adotados em situações em que se presencia ou se convive com a greve de fome.

O Código Penal brasileiro, nos artigos 135 e 146, assim delibera

Art. 135 - Deixar de prestar assistência, quando possível fazêlo sem risco pessoal, à criança abandonada ou extraviada, ou à pessoa inválida ou ferida, ao desamparo ou em grave e iminente perigo; ou não pedir, nesses casos, o socorro da autoridade pública:

Pena - detenção, de um a seis meses, ou multa.

Parágrafo único. A pena é aumentada de metade, se da omissão resulta lesão corporal de natureza grave, e triplicada, se resulta a morte.

Art. 146 - Constranger alguém, mediante violência ou grave ameaça, ou depois de lhe haver reduzido, por qualquer outro meio, a capacidade de resistência, a não fazer o que a lei permite, ou a fazer o que ela não manda:

Pena - detenção, de três meses a um ano, ou multa.

Aumento de pena

$[\ldots] \S 3^{\circ}$ - Não se compreendem na disposição deste artigo:

I - a intervenção médica ou cirúrgica, sem o consentimento do paciente ou de seu representante legal, se justificada por iminente perigo de vida;

II - a coação exercida para impedir suicídio.

O Conselho Federal de Medicina (CFM), por sua vez, em resolução de número 1.931/2009, esclarece alguns deveres do médico no capítulo direcionado aos direitos humanos. No artigo 26, diz ser vedado ao médico o desrespeito à vontade

09 Mas a "proteção" dos direitos não implica "interferência" na maneira de exercê-los. O dever de velar pela integridade dos prisioneiros é, fundamentalmente, um dever negativo. Isso quer dizer que a obrigação de disponibilizar todos os meios possíveis para que eles sejam alimentados corretamente e de forma saudável, para evitar doenças como a SIDA ou a tuberculose, para protegê-los da violência física ou sexual, etc. Mas isso não pode significar que a administração penitenciária "obrigue positivamente" os presidiários, salvo exceções, como a saúde pública, a usar esses meios. Isso implicaria uma clara interferência em sua liberdade pessoal, com fronteiras totalitárias. E isso um Estado Democrático de Direito não pode permitir. LORDA, Pablo Simón. Huelga de hambre y Estado de derecho. El País, 2006. Disponível em: https://elpais.com/diario/2006/09/26/ salud/1159221603_850215.html. Acesso em: 10 mar. 2018. 
do praticante da greve de fome, capaz física e mentalmente, ou sua alimentação compulsória, devendo apenas informá-lo sobre as consequências da greve e, na hipótese de risco iminente de morte, tratá-lo.

Nesse viés, adota o contexto brasileiro a liberação da greve de fome, bem como a proibição da alimentação compulsória. Cabe ao médico analisar a situação e prestar esclarecimentos. Entende-se essencial o respeito à autonomia da vontade, consubstanciado, nos artigos 22 e 24 da mesma resolução, em demais proibições ao médico.

Art. 22. Deixar de obter consentimento do paciente ou de seu representante legal após esclarecê-lo sobre o procedimento a ser realizado, salvo em caso de risco iminente de morte.

Art. 24. Deixar de garantir ao paciente o exercício do direito de decidir livremente sobre sua pessoa ou seu bem-estar, bem como exercer sua autoridade para limitá-lo.

O artigo 28 destaca importante questão ao ressaltar a irrelevância da instituição em que o paciente se encontra para que seu interesse seja respeitado. Os presos possuem direitos que devem servalorizados e preservados independentemente do crime que cometeram. A Constituição de 1988, no inciso XLIX do artigo $5^{\circ} \mathrm{diz}$ ser "[...] assegurado aos presos o respeito à integridade física e moral" e positiva $\mathrm{o}$ entendimento do CFM.

De fato, não se pode impor pena privativa de liberdade sem garantir os direitos inalienáveis do ser humano, sem protegêlo de um ambiente que não preserve a qualidade de vida [...] É preciso que nos estabelecimentos penitenciários evitem-se a humilhação e a brutalidade física e moral. ${ }^{10}$

Os artigos 22 e 26, porém, abrem exceção ao risco de morte, respaldados pelo Código Penal. Se o profissional constata risco iminente, permite-se a ele a realização do tratamento. Possível justificativa para essa atitude seria o argumento supramencionado de que o grevista não se encontraria mais em situação de manifestação, mas em estado de debilidade tamanha que passam a ser considerados pacientes e incapazes de manifestar-se, devendo o médico atuar para a proteção de sua vida.

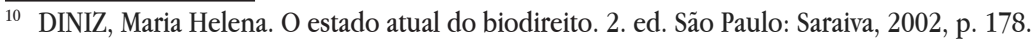


Sabe-se, como previamente ressaltado, que o caráter primordial da greve de fome é o de manifestação e essa característica seria mais um argumento a permitir a intervenção médica em casos de risco à vida. Como explicitado pelo autor J. García-Guerrero, o grevista em si não deseja morrer, fato comprovado pelo não comprometimento da saúde da pessoa na maioria das greves de fome, que geralmente não são conduzidas a seu estágio final ${ }^{11}$.

Questiona-se, porém, o que fazer quando o grevista possui consciência de que suas atitudes poderiam levar à morte e, ainda assim, decide assumir as eventuais consequências. Sua atitude não seria suicida primordialmente: ele não deseja morrer, mas aceita a morte se preciso. Ainda que desejasse, nenhum crime cometeria, pois, o suicídio não se configura como tal no direito brasileiro.

Tendo isso afirmado, não seria, afinal, a possível perda da vida o aspecto essencial e mais impactante da greve? E, se a dignidade consiste em defender valores inerentes à condição humana, o que seria mais contraditório do que forçar o abandono da luta por seus ideais e a manutenção da vida em oposição aos seus desejos? É sob esse aspecto que é possível diferenciar a greve do caso dos anões e responder a pergunta anteriormente feita: a greve de fome, assegurada pela autonomia da vontade, fere ou reafirma a dignidade humana? Ao observar por outro viés, não se torna inviável entender que a greve de fome reafirma a dignidade humana e permite ao homem a autonomia e a capacitação para buscar seus ideais e cumprir os objetivos de vida que a si mesmo propõe. A morte é a certeza da humanidade, mas viver como almeja é utopia para muitos.

Nesse sentido, cabe fazer novamente referência à prisão de Guantánamo, onde foi verificada a alimentação compulsória de diversos presos, e reafirmar, por texto de Daniel de Barros, o entendimento acima mencionado.

A notícia mais inquietante, contudo, é que esses homens vêm sendo alimentados à força. Os que mantém a recusa alimentar e correm risco de morte são amarrados a cadeiras e têm uma sonda inserida pelo nariz até o estômago, por onde uma alimentação pastosa é inserida. Eticamente isso não poderia

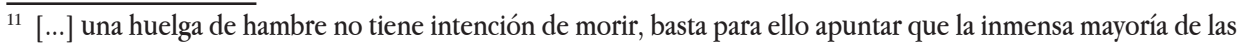
huelgas de hambre hechas en prisión no pasan de la fase que sólo implica el sacrificio personal de no comer, sin comprometer la salud de quién la realiza; tampoco creo que en los casos extremos haya intención suicida ya que en el ánimo de quien la hace prevalece el propósito de luchar por una idea sobre la intencionalidad de morir, la propia muerte solo es en este caso una consecuencia posible de esa lucha. GARCÍA-GUERRERO, J. La huelga de hambre en el ámbito penitenciario: aspectos éticos, deontológicos y legales. Disponível em: http:// scielo.isciii.es/scielo.php?script $=$ sci_arttext $\&$ pid $=\$ 1575-06202013000100003$. Acesso em: 10 mar. 2018.
} 
ser feito. Se a decisão do sujeito de não se alimentar foi livre e racional, inclusive com o risco de morte, não há justificativa para alimentá-lo contra seu desejo. Mesmo a Associação Médica Mundial afirma que a alimentação forçada nunca é eticamente aceitável, uma vez que desrespeita a autonomia do sujeito.

Sim, é extremamente angustiante saber que aqueles homens podem morrer a qualquer minuto por algo reversível imagine-se para o médico, que está ao lado do sujeito. Mas é essa perspectiva que dá maior impacto ao protesto, pois se fica acertado de saída que nada de pior vai acontecer, sua força diminui. Como no conto de Kafka, em que o faquir fica tantos anos sem se alimentar - e nunca morre - que acaba esquecido pelo público. ${ }^{12}$

Embora a doutrina não afirme dessa forma, não se pode desconsiderar ou deixar de levar ao debate a visão de que a liberdade concedida ao médico para tratar o paciente em iminente risco de morte limita-se aos grevistas que não consideravam a perda da vida como opção e em nenhum momento atestaram manifestação de vontade que alegasse o contrário.

Entender que um grevista disposto a todas as consequências na luta por seus objetivos deve ser tratado e medicado quando em sérios riscos culmina em contradição gravíssima e coloca em risco outros institutos do nosso direito. Como explicitado pelo já citado médico e especialista em bioética, Pablo Simón Lorda, desconsiderar uma vontade previamente manifesta por uma situação de impossibilidade comunicativa atual seria equivalente ao não respeito aos testamentos vitais, que dispõe justamente sobre ações a serem tomadas nos momentos finais de vida. ${ }^{13}$

Assim, o entendimento que restringe a liberdade do médico ao tratamento de grevistas que colocaram a morte como limite a sua manifestação solidifica-se pelas declarações realizadas em diversos países do mundo, embora encontre barreiras no contexto brasileiro.

\footnotetext{
${ }^{12}$ BARROS, Daniel Martins de. A greve de fome e a ética. Disponível em: http://emais.estadao.com.br/blogs/ daniel-martins-de-barros/a-greve-de-fome-e-a-etica/. Acesso em: 26 jul. 2017.

${ }^{13}$ LORDA, Pablo Simón. Huelga de hambre y Estado de derecho. El País, 2006. Disponível em: https://elpais. com/diario/2006/09/26/salud/1159221603 850215.html. Acesso em: 10 mar. 2018.
} 


\section{A GREVE DE FOME DE PRESIDIÁRIOS NA LEGISLAÇÃO ESTRANGEIRA: AS DECLARAÇÕES DE MALTA E DE TÓQUIO E O CÓDIGO PENAL PORTUGUÊS}

Convenções e legislações mundo afora preocuparam-se em adentrar o assunto da greve de fome e as atitudes que deveriam ser tomadas em relação a ela.

A Declaração de Malta sobre Pessoas em Greve de Fome, realizada na $43^{\mathrm{a}}$ Assembleia Médica Mundial, em Malta, em 1991, procurou instruir os médicos em relação aos praticantes da greve de fome. Declara ser dever do médico, que decidiu por fornecer assistência ao grevista, o respeito à autonomia da vontade, bem como o requerimento do consentimento do paciente antes de qualquer prática que nele possa ser realizada, destacando haver casos emergenciais em que cabe ao médico agir em favor de interesses maiores da pessoa em questão, especialmente quando o grevista estiver confuso ou impossibilitado de emitir opinião clara sobre o destino de sua vida.

Em situações em que há risco à vida do paciente, a Declaração afirma que é da pessoa que o sofre a decisão de permitir ou não intervenção médica. Salva-se ao médico, porém, em casos em que o grevista não aceita o tratamento em situação hipotética de coma ou risco de vida, o direito de não concordar com a decisão que fora previamente manifesta pelo paciente e, se assim feito, alertá-lo para que seja autorizado a receber assistência de outro profissional.

Em situações mais gerais, a Declaração estabelece ainda a necessidade de um acompanhamento diário do grevista pelo profissional, averiguando seus desejos e manifestações e registrando-os. Veda-se a ele a tentativa de influenciar pela interrupção da greve de fome, bem como omitir informações ao paciente.

Entende-se, assim, uma posição mundial contra a alimentação forçada do grevista, permitindo a ele assumir as consequências de escolhas racionalmente tomadas e atestadas, ainda que essas consequências incluam a morte.

Os Códigos de Ética Médica espanhol, português e italiano, por exemplo, respectivamente dos anos 1985, 1999 e 2006, já desobrigaram os seus médicos deste incômodo dever, respectivamente através dos artigos $9^{\circ}, 57$ e 53 dos seus códigos, confirmando a tendência mundial. O código espanhol prevê a possibilidade de encaminhamento para decisão judicial. O italiano proíbe o médico de participar de iniciativas constritivas ou manobras coativas para alimentação. 
O português proíbe expressamente o médico de participar ou adotar a iniciativa de alimentação coerciva. ${ }^{14}$

Semelhantemente, a Declaração de Tóquio, apreciada na 29a Assembleia Geral da Associação Médica Mundial, em 1975, expressa a necessidade do respeito às decisões do paciente que possui total capacidade de raciocínio e a importância da comprovação dessa capacidade por profissionais. Seria recomendado ao médico fornecer ao paciente água, sal e vitaminas, diminuindo os riscos ao organismo e evitando a descaracterização da greve de fome. Essa atitude representaria não somente um auxílio providencial, como o cumprimento do dever de respeitar as atitudes e manifestações realizadas pelo indivíduo.

Analisando ainda a legislação internacional, crê-se importante citar o Código Penal português, que traz duas hipóteses em relação a tratamentos médicos, que podem ser aplicadas aos casos da greve de fome e acarretariam importantes distinções.

O artigo 156 do Código Penal português prevê a impossibilidade de realização de tratamentos médicos sem consentimento do paciente. Ressalta, porém, que a intervenção arbitrária não seria punida quando não se pudesse concluir que o consentimento seria recusado ou quando o consentimento não pudesse ser obtido e não houvesse tempo de espera, sendo iminente o risco à vida ou à saúde. Semelhantemente, não haveria punição, nos casos em que a intervenção ultrapassasse os limites do consentimento ofertado, se tal procedimento fosse necessário para evitar danos maiores. Aplicando ao caso concreto, respeitar-se-ia a vontade do grevista, permitindo ao médico intervir quando não se tem certeza sobre sua intenção e há perigo de morte ou grave consequência.

Cabe ressaltar os casos em que a greve de fome é realizada visando o suicídio. Embora entenda-se ser essa greve uma forma de protesto e manifestação, não caracterizando o grevista como suicida, não se pode negar um eventual propósito de concretizar a morte. Nessa situação, prevaleceria o respeito à vontade manifesta pelo grevista e deveria o médico ser capaz de respeitá-la. Apesar disso, o inciso III do artigo 154 do mesmo código ressalta que não seria punido aquele que constrange alguém a determinada atividade se visa evitar o suicídio. Assim, entra-se em dilema no qual prevalece o entendimento da não punição do médico que optar

${ }_{14}$ BONAMIGO, Elcio Luiz. A reforma do código de ética médica: pontual ou estrutural? Disponível em: http:// www.portalmedico.org.br/novocodigo/artigo3.htm. Acesso em: 26 jul. 2017. 
por preservar a vontade do paciente, ao mesmo tempo em que se protege e justifica atitude contrária que o profissional venha a tomar, respeitando o desejo do grevista.

\section{O CONSELHO NACIONAL DE POLÍTICA CRIMINAL E PENITENCIÁRIA E A GREVE DE FOME DOS PRESIDIÁRIOS}

O Conselho Nacional de Política Criminal e Penitenciária (CNPCP) é um órgão de execução penal criado em 1980 com o intuito de promover avaliações constantes sobre o sistema penitenciário e criminal brasileiro e, consequentemente, elaborar políticas e planos para auxiliar no crescimento e evolução do Brasil no assunto. Em 2005, o CNPCP implantou uma resolução contendo o Manual de Atendimento em Situações Especiais, referente à greve de fome dos presidiários. Alegava que o Plano Nacional de Saúde Penitenciária tratava das situações comuns no dia a dia do sistema penitenciário, mas não das situações especiais, sendo, assim, necessário um guia padrão para auxiliar no tratamento designado a essas ocorrências. Esse guia, embora não de força imperativa, serviria para basear e orientar as decisões tomadas pelos médicos.

Em um primeiro momento, o manual introduz o assunto, destacando a greve de fome como um meio de manipulação social, consecução de objetivos políticos e busca por melhorias no sistema prisional, demonstrando, também, a possibilidade atual de ampliação desse meio de luta.

Posteriormente, a resolução utiliza-se da Constituição brasileira, do Código Penal brasileiro e da própria Declaração de Malta, bem como de outros códigos, para embasar o posicionamento tomado. Este corrobora a ideia de que a liberdade, ou a autonomia da vontade, como tratada neste artigo, é essencial, mas não pode sobrepor-se à vida do indivíduo. A vida seria o bem supremo e de valor não apenas individual, mas referente à toda sociedade.

No caso das greves de fome, a liberdade do detento de recusar alimentação deve ser respeitada. [...] Todas as intervenções a serem realizadas pela equipe devem ser consentidas pelo paciente, salvo nos casos em que haja perigo de morte iminente. Nestes, a decisão técnica é soberana, a fim de preservar-lhe a vida. ${ }^{15}$

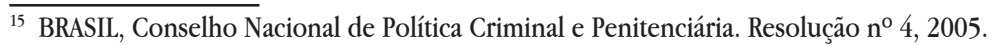


Por fim, o manual explica o processo corporal ocasionado pela greve de fome, seus riscos e consequências, e estabelece uma série de diretrizes a serem levadas em consideração. Entre elas, destaca a necessidade de um médico que conheça todo o possível sobre a história do paciente, bem como que realize todos os exames imprescindíveis. Demonstra, ainda, o estágio degradante ao qual a greve pode levar, em que não se torna viável a consideração de manifestações cognitivas, intelectuais, do paciente, autorizando a intervenção médica para a reversão do quadro.

Além das já mencionadas, outras recomendações foram emitidas, como o monitoramento diário de detentos que já realizam a greve há mais de 72 horas e o seu encaminhamento a psicólogos e assistentes sociais.

\section{ITINERÁRIO ÉTICO}

2.4. O grevista de fome deve ser profissionalmente informado pelo médico das consequências clínicas de uma greve de fome, e de qualquer perigo específico para o seu caso particular. Uma decisão informada só pode ser tomada na base de comunicação clara. $\mathrm{O}$ intérprete pode ser usado se ele indicar. 2.6. No tratamento de infecções é aconselhável que o paciente aumente a ingestão de líquidos (ou aceite soluções salinas intravenosas), o que é frequentemente aceito pelo grevista de fome. Uma recusa para aceitar tal intervenção não deve prejudicar qualquer outro aspecto do cuidado de saúde do paciente. Qualquer tratamento administrado ao paciente deve ser feito com sua aprovação.

\section{INSTRUÇÕES CLARAS}

O médico deverá averiguar diariamente se o paciente deseja continuar com a greve de fome. O médico também deve averiguar diariamente quais os desejos do paciente com respeito ao tratamento caso fique impossibilitado de tomar uma decisão consciente. Estes achados devem registrar-se nos prontuários e mantidos confidencialmente.

4. ALIMENTAÇÃO ARTIFICIAL

Quando o grevista de fome estiver confuso ou impossibilitado de tomar uma decisão incólume ou entrar em estado de coma, o médico estará livre para tomar uma decisão a favor do tratamento adicional que considere ser do melhor interesse do paciente e sempre levando em conta a decisão que esse 
tomou durante a greve de fome e o que consta do preâmbulo desta Declaração. ${ }^{16}$

Ainda que destaque a importância de conhecer os desejos do paciente e documentá-los, o Manual de Atendimento em Situações Especiais possibilita e recomenda a intervenção médica em caso de risco iminente de morte, colocando a vida como bem predominante e fundamental. Respeita os desejos do grevista, mas limita sua vontade à dignidade humana consubstanciada no ato de viver. Seguindo as diretrizes supracitadas, o caso envolvendo Marcos Willian Herbas Camacho foi o primeiro em que a resolução foi exercida.

Marcos foi indicado como o líder do Primeiro Comando da Capital, considerada a maior organização criminosa brasileira. No presídio, junto a outros presos, permaneceu 11 dias sem se alimentar, em protesto contra a rigidez excessiva que enfrentavam. A greve não logrou vitória, porém, segundo o relatado por Carlos Weis, conselheiro responsável pela visita aos detentos, o manual foi aplicado integralmente, permitindo aos presos a realização da greve, mas autorizando intervenção médica em situações emergenciais. ${ }^{17}$

\section{ROBERT ALEXY E OS DIREITOS FUNDAMENTAIS}

Por ser extremamente relevante, ter grande impacto social e por tratar-se da vida humana, entende-se válido um desdobramento judicial da questão da greve de fome pelos presidiários, ainda que haja legislação e convenções internacionais a respeito. Compreende-se o desespero de familiares contrários à prática, o senso ético de dever do médico ou mesmo as normas morais, e por vezes religiosas, da sociedade em defesa da vida a qualquer custo.

Os Códigos de Ética Médica espanhol, português e italiano, por exemplo, respectivamente dos anos 1985, 1999 e 2006, já desobrigaram os seus médicos deste incômodo dever, respectivamente através dos artigos $9^{\circ}, 57$ e 53 dos seus códigos, confirmando a tendência mundial. O código espanhol prevê a

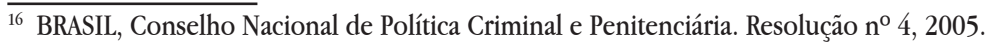

${ }^{17}$ PINHEIRO, Aline. Vida é um bem maior do que o direito de protestar. Disponível em: https://www.conjur. com.br/2007-jan-27/vida_bem_maior_direito_protestar. Acesso em: 15 nov. 2017.
} 
possibilidade de encaminhamento para decisão judicial. ${ }^{18}$

Para analisar individualmente a questão, cada pessoa utiliza critérios valorativos que não são comuns a todos, visto ser a sociedade composta dos mais variados critérios axiológicos e entendimentos de mundo. Daí a possibilidade de litígio, ora defendendo direitos fundamentais que muitos julgam ter as convenções e códigos desrespeitados, ora apresentando especificidades próprias dos casos concretos.

Sob essa argumentação, cabe adentrar a teoria do jurista alemão Robert Alexy sobre a colisão de direito fundamental, apresentando mais uma possibilidade de discussão sobre as possíveis resoluções do caso da greve de fome dos presidiários. Cabe antes dizer, porém, que este artigo não visa defender a teoria apresentada, mas fornecer outros parâmetros para a discussão, baseando-se em uma teoria amplamente consolidada e, inclusive, presente no Código de Processo Civil brasileiro.

\subsection{A TEORIA DA COLISÃO ENTRE DIREITOS FUNDAMENTAIS}

Robert Alexy, considerado um dos grandes influenciadores do direito, desenvolveu uma teoria sobre a colisão dos direitos fundamentais. A esses direitos, segundo a teoria dos princípios, foi ofertada uma equivalência aos princípios e, por isso, passíveis de colisão e ponderação. ${ }^{19}$ Isso não significa dizer que os direitos fundamentais não podem se constituir em regras, mas apenas afirma que mesmo as regras em questão estarão circundadas pelos princípios. Cabe a ressalva de que existe a defesa de uma teoria das regras dos direitos fundamentais, ${ }^{20}$ mas essa não condiz com o entendimento deste artigo e, assim, não serve ao propósito do mesmo.

Com a crescente importância dos direitos fundamentais, muito se discutiu sobre a solução possível para resolver colisões que poderiam eventualmente surgir. Em um processo em que uma parte argumentasse seu direito fundamental à liberdade de expressão e a outra, o direito fundamental à honra, qual deveria

${ }_{18}$ BONAMIGO, Elcio Luiz. A reforma do código de ética médica: pontual ou estrutural? Disponível em: http:// www.portalmedico.org.br/novocodigo/artigo3.htm. Acesso em: 26 jul. 2017.

19 As colisões dos direitos fundamentais acima mencionadas devem ser consideradas segundo a teoria dos princípios, como uma colisão de princípios. O processo para a solução de colisões de princípios é a ponderação. ALEXY, Robert. Colisão e ponderação como problema fundamental da dogmática dos direitos fundamentais. Palestra proferida na casa Rui Barbosa, em 10.12.1998. Tradução de Gilmar Ferreira Mendes. Material da 6a aula da Disciplina Direitos e Garantias Fundamentais, ministrada no Curso de Especialização TeleVirtual em Direito Constitucional - UNISUL - IDP - REDE LFG, p. 7.

${ }^{20}$ Ibidem, p. 7, 8 e 9. 
sobressair? Semelhantemente, caso colidissem o direito fundamental à privacidade e o direito fundamental à informação, qual deveria ser respeitado? Pensando nisso, Alexy parte de uma ordem deontológica, não possuindo a intenção de estabelecer valores ou seguir critérios políticos e morais, mas oferecer uma forma racional e lógica para contrapor direitos fundamentais. Realiza, então, uma ponderação através do condicionamento da colisão às circunstâncias fáticas e jurídicas analisadas no caso concreto.

Em sua teoria, Alexy conjuga a razoabilidade (ou racionalidade) com a proporcionalidade, permitindo a formação da máxima da proporcionalidade para solucionar colisões. Entende, assim, nesta, três etapas: adequação, necessidade e proporcionalidade em sentido estrito (ponderação).

$\mathrm{Na}$ primeira etapa, questiona-se se o meio utilizado para efetivar o direito fundamental é adequado, ou seja, se a aplicação do princípio em questão atinge o seu objetivo por um meio considerado justo ou bem justificado. Se ficar comprovado que não ocorreu a adequação de um direito fundamental, o direito opositor torna-se procedente.

Na segunda etapa, analisa-se se o meio é necessário, ou seja, inexiste forma menos gravosa ou menos custosa para exercer o direito. De modo semelhante à submáxima de adequação, se havia outro meio menos lesivo para a realização do princípio, o direito opositor prepondera.

$\mathrm{Na}$ terceira etapa, concebendo os meios utilizados como adequados e necessários, adentra-se a proporcionalidade em sentido estrito, dando seguimento ao exame das circunstâncias jurídicas em questão e considerando a importância e o grau de prejuízo da efetivação de cada direito fundamental. Ocorre nesta fase uma nova subdivisão. De início, busca-se examinar a intensidade da intervenção, as consequências ou prejuízos que a prevalência de um direito acarretará ao outro.

A seguir, cumpre especificar a importância de cada direito fundamental. Por fim, realiza-se uma ponderação em sentido estrito, colocando em oposição a importância do direito e as consequências que o mesmo causará no outro, para, assim, afirmar ser essa relação plausível.

\subsection{APLICAÇÃO DA TEORIA AOS CASOS CONCRETOS}

É possível aplicar a teoria da colisão a casos já mencionados neste artigo. Colocar-se-ia em conflito o direito fundamental à vida e o direito fundamental à 
liberdade, consubstanciado na autonomia da vontade. Como a teoria não se aplica a direitos pertencentes à mesma pessoa, por não entender haver conflito, é essencial mencionar que o direito à vida seria entendido como pertencente à sociedade como um todo, um bem social, explicitado pelo dever fundamental de proteção à vida.

O caso dos detentos da prisão de Guantánamo, como já mencionado em referência ao texto de Daniel de Barros, ressalta uma situação em que a greve de fome foi usada como protesto pela negligência com que foram tratados desde o âmbito jurídico. Não havia uma condenação perpétua propriamente dita e muito menos a certeza de um tempo para o cumprimento da pena. Diante dessa situação, os grevistas foram alimentados à força, com a inserção de sondas que iam desde 0 nariz até o estômago. Nesse caso, segundo a teoria de Alexy, não se chega sequer à colisão. $\mathrm{O}$ problema tem fim já no âmbito da razoabilidade, em específico na adequação. Os meios aplicados não foram adequados, pois, apesar de atingirem o fim almejado, no caso, a alimentação para evitar a morte, não foram justos e acabaram por interferir em princípios como a dignidade humana, realizando uma alimentação forçosa, dolorosa e próxima a níveis de tortura. Reafirmando a análise, ainda que os meios tivessem sido adequados, não seriam necessários, pois haveria formas menos gravosas e mais humanizadas para garantir o direito de proteção à vida.

Outro caso foi o do palestino Mohamed Al Qeiq, que permaneceu em greve de fome por 94 dias para exigir sua libertação, acreditando ser sua prisão injusta. Al Queiq, durante todo o período da greve, somente bebeu água, por vezes provida de sais minerais. Chegou ao estágio em que não conseguia falar ou ouvir, perdeu 13 quilos e sofria risco iminente de morte. Antes da decisão final israelense, foi internado em hospital e a ele exigido que não saísse de lá. Embora tenha abandonado seu protesto após acordo com o governo de Israel e não tenha reclamado das intervenções médicas, é possível suscitar um conflito entre a liberdade de Al Qeiq e a proteção à sua vida por uma visão que entende que qualquer interferência seria inapropriada.

Segundo a teoria de Alexy, o conflito em questão atenderia às fases da adequação e da necessidade. $\mathrm{O}$ direito de liberdade e o dever de proteção à vida foram adequados e necessários, pois, ao realizar a greve e ao internar o paciente para evitar a morte, respectivamente grevista e autoridades realizaram ações correspondentes aos seus fins de forma lícita e sem excessos, não interferindo em demais princípios. Cabe lembrar que Al Qeiq não desejava morrer e não houve 
indícios de que aceitou esse risco, vontade provada ao ingerir água com minerais e ter como objetivo do protesto sua libertação. Tendo assim entendido, entra-se no real conflito, na proporcionalidade em sentido estrito.

Analisa-se, primeiramente, os prejuízos que a concreção de um direito gerará ao outro. Se prioriza-se o dever fundamental de proteção à vida acima de tudo, adotando medidas que possam colocar em risco o caráter de greve, vê-se que uma intervenção grave seria exigir que o preso se alimentasse concretamente, além do líquido que ingeria. Uma intervenção moderada seria a internação do grevista e a alimentação por sonda. Já uma intervenção leve, no sentido de gerar o menor prejuízo possível ao direito fundamental de liberdade, consubstanciado na greve, seria o que foi efetivamente realizado: manter o interno sobre monitoramento hospitalar, em local seguro, porém sem forçá-lo a atitudes que não desejar. Por outro lado, se prioriza-se o direito fundamental à liberdade, entende-se que gravemente afetaria a vida realizar a greve sem permitir qualquer auxílio médico. Um prejuízo moderado seria a permissão de acompanhamento médico e a ingestão de sais minerais que permitissem a sobrevida, como foi realizado, segundo a reportagem que relata o caso. ${ }^{21}$ Por sua vez, o modo de realização da greve que geraria o prejuízo considerado mais leve à vida seria a mesma ingestão de líquidos mineralizados, bem como a autorização para o tratamento médico em caso de risco iminente de morte, permitindo até mesmo a alimentação. Dessa forma, entende-se que a precedência do dever fundamental de proteção à vida geraria prejuízos menores ao direito opositor do que a opção pelo direito fundamental à liberdade.

Em seguida, parte-se para o grau de importância de cada direito fundamental. Analisando pelo lado do dever de proteção à vida, um grau de importância baixo seria apenas tentar manter a vida sem atentar-se aos motivos da greve, buscando atender os interesses do governo e preservar sua imagem perante a população. Um grau moderado seria realizar a proteção atendendo somente a apelos sociais ou mesmo da família. Um grau de importância alto, por sua vez, seria proteger a vida por entender ser ela um bem social e de extrema importância, preocupando-se com o estado de dignidade do grevista, como aparenta ser o caso mencionado. Por outro viés, examinando pelo olhar do direito fundamental à liberdade, no caso, a realização da greve, um grau de importância baixo seria a mera busca por manipulação e atribuição

\footnotetext{
${ }^{21}$ Com risco de morte, preso palestino interrompe greve de fome após 94 dias. UOL Notícias, 26 fev. 2016. Disponível em: https://noticias.uol.com.br/ultimas-noticias/efe/2016/02/26/com-risco-de-morte-presopalestino-interrompe-greve-de-fome-apos-94-dias.htm. Acesso em: 15 nov. 2017.
} 
de culpa, em caso de morte, ao governo. Um grau moderado seria a liberdade em função da realização dos ideais do grevista, embora pudessem ser alcançados de outro forma. Um grau alto de importância seria atribuído ao grevista que exercesse seu direito almejando justiça que não havia sido concedida a ele por outros modos, durante longo período de tempo, lutando por seus ideais e exercendo sua liberdade para alcançar o que considera ser digno, como ocorre na história de Al Qeiq. Assim, a ambos atribuir-se-ia o mesmo alto grau de importância.

Por último, parte-se para a ponderação em sentido estrito, contrapondo os grau já analisados e chegando à conclusão de que, nesse caso, a intensidade da intervenção no direito fundamental à liberdade, causado pelo dever de proteção à vida, foi leve, e a importância desse dever de proteção à vida foi alto. Como resultado, torna-se precedente o dever de proteção à vida.

É importante ressaltar que o caso foi analisado partindo de uma colisão levantada por uma defesa que consideraria qualquer intervenção inadequada. Sabese que Mohammed Al Qeiq não desejava morrer e, por isso, pode ter sido conivente com as decisões a respeito de sua saúde, evitando um conflito que poderia surgir. Em outros casos, porém, esse conflito torna-se evidente e, dependendo da análise do caso concreto, o direito à liberdade pode preceder, especialmente em casos em que o preso não coloque a morte como empecilho à greve, aceitando-a, caso necessário.

Além disso, embora seja a ponderação de Alexy de extrema importância, cabe analisar as regras instituídas no país, que, no caso brasileiro, indicam para a proteção do direito à vida. Não se pode renegá-las de forma imprudente, buscando somente a ponderação, pois afetaria o entendimento doutrinário consolidado, bem como a segurança jurídica proporcionada pela legislação brasileira. Preciso é seguir o estabelecido, porém com cautela, abrindo as portas para as mudanças e as peculiaridades de cada situação.

\section{CONCLUSÃO}

É necessário eliminar o olhar excludente da sociedade sobre os presos e enxergá-los como seres humanos dotados de direitos e deveres. A prisão não visa somente punir, mas reconstituir os valores sociais aparentemente perdidos na pessoa praticante do delito para, então, reintroduzi-los na sociedade. Afirma-se isso 
baseado em um contexto brasileiro que não adota a pena de morte e, teoricamente, não encerra as possibilidades de uma vida digna na sentença afirmativa do crime. Cabe ressaltar que não se defende a impunidade ou a relativização das penas, mas a garantia do respeito à dignidade e aos direitos fundamentais assegurados a todos.

Tendo dito isso, prossegue-se para concluir que, no direito brasileiro, a autonomia da vontade subordina-se à dignidade humana. Deve o preso, independentemente do delito que tenha praticado, ter sua vontade respeitada e promovida em sua máxima medida, desde que não interfira na dignidade, entendida como valor coletivo. Por esse motivo, a legislação brasileira instrui o profissional de saúde a respeitar as decisões do paciente, no caso, o grevista, e oferecer meios propícios para a sua concretização. Cabe ao médico interferir apenas quando se visualiza iminente risco de morte, por entender que o grevista estaria, possivelmente, em estado incapaz de manifestar-se e que o objetivo da greve seria um protesto e não o suicídio. Por outro lado, é possível defender a análise do caso concreto e, apoiando-se em legislação internacional, procurar atender o interesse do preso que vê na greve, independente de uma evidente morte, a concreção de sua dignidade na luta por seus ideais.

Este artigo, como dito na introdução, não almeja proferir sentença e emitir um posicionamento fixo. Crê-se que há muito ainda a analisar e discutir mundialmente, pois, quando se trata da vida e de atos humanos, poucas são as situações que adquirem ares de certeza.

\section{REFERÊNCIAS}

ALEXY, Robert. Colisão e ponderação como problema fundamental da dogmática dos direitos fundamentais. Palestra proferida na casa Rui Barbosa, em 10.12.1998. Tradução de Gilmar Ferreira Mendes. Material da 6a aula da Disciplina Direitos e Garantias Fundamentais, ministrada no Curso de Especialização TeleVirtual em Direito Constitucional - UNISUL - IDP - REDE LFG.

AMARAL, Francisco. Direito Civil: introdução. Rio de Janeiro: Renovar, 2008.

BARROS, Daniel Martins de. A greve de fome e a ética. Disponível em: http://emais. estadao.com.br/blogs/daniel-martins-de-barros/a-greve-de-fome-e-a-etica/. Acesso em: 26 jul. 2017. 
BARROSO, Luís Roberto. ADignidade da Pessoa Humana no Direito Constitucional Contemporâneo: Natureza Jurídica, Conteúdos Mínimos e Critérios de Aplicação. Versão provisória para debate público. Mimeografado, dezembro de 2010. Disponível em: http://www.luisrobertobarroso.com.br/wp-content/uploads/2010/12/ Dignidade_texto-base_11dez2010.pdf. Acesso em: 13 jul. 2017.

BONAMIGO, Elcio Luiz. A reforma do código de ética médica: pontual ou estrutural? Disponível em: http://www.portalmedico.org.br/novocodigo/artigo3. htm. Acesso em: 26 jul. 2017.

BRASIL. Conselho Nacional de Política Criminal e Penitenciária. Resolução $\mathrm{n}^{\mathrm{O}}$ $4,2005$.

COM RISCO de morte, preso palestino interrompe greve de fome após 94 dias. UOL Notícias, 26 fev. 2016. Disponível em https://noticias.uol.com.br/ultimas-noticias/ efe/2016/02/26/com-risco-de-morte-preso-palestino-interrompe-greve-de-fomeapos-94-dias.htm. Acesso em: 15 novembro 2017.

DINIZ, Maria Helena. O estado atual do biodireito. 2. ed. São Paulo: Saraiva, 2002.

GARCÍA-GUERRERO, J. La huelga de hambre en el ámbito penitenciario: aspectos éticos, deontológicos y legales. Disponível em: http://scielo.isciii.es/ scielo.php?script $=$ sci_arttext\&pid=\$1575-06202013000100003. Acesso em: 10 mar. 2018.

LIEBL, Caroline. GrevedeFome: oMitodoMeioNãoViolentode ResoluçãodeConflitos. Rev. Fac. Dir. Sul de Minas, Pouso Alegre, v. 31, n. 2: 77-104 jul./dez. 2015. Disponível em: $\quad$ http://www.fdsm.edu.br/adm/artigos/418ff255817260b3c6d54b712ae68441. pdf. Acesso em: 13 julho 2017.

LORDA, Pablo Simón. Huelga de hambre y Estado de derecho. El País. Disponível em: https://elpais.com/diario/2006/09/26/salud/1159221603_850215.html. Acesso em: 10 mar. 2018.

MARTINEZ, Vinício. Estado de Direito. Revista Jus Navigandi, Teresina, ano 11, n. 918, 7 jan. 2006. Disponível em: https://jus.com.br/artigos/7786. Acesso em: 5 jul. 2017.

PINHEIRO, Aline. Vida é um bem maior do que o direito de protestar. Disponível 
em: https://www.conjur.com.br/2007-jan-27/vida_bem_maior_direito_protestar. Acesso em: 15 novembro 2017.

Recebido em: 30/07/2018

Aceito em: 12/02/2019 